\title{
Graphene for Flexible Photovoltaic Devices
}

\author{
Kwadwo Mensah-Darkwa ${ }^{1}$, Rita Namoe Tabi ${ }^{1}$, Pawan K. Kahol ${ }^{2}$ and Ram K. Gupta ${ }^{2,3, *}$ \\ ${ }^{1}$ Department of Materials Engineering, College of Engineering, Kwame Nkrumah, University of Science and \\ Technology, Kumasi, Ghana \\ ${ }^{2}$ Department of Chemistry, Pittsburg State University, Pittsburg, KS 66762, USA \\ ${ }^{3}$ Kansas Polymer Research Center, Pittsburg State University, Pittsburg, KS 66762, USA
}

\begin{abstract}
Flexible photovoltaic devices (FPD's) are emerging as next-generation technology in photovoltaic research. FPD's have attracted great research attention because of their broad potential applications especially in wearable devices, portable electronics, integrated textiles, unmanned aerial vehicles, transportation, and military etc. The existing technologies have evolved over the years, improving efficiency and performance of photovoltaic devices. However, these technologies mostly rely on rigid electrodes that are brittle, costly and chemically unstable. For FPD's to become practical, new materials that offer inherent flexibility without compromising on mechanical and optical properties must be the focus. Researchers have made significant advances over the past decade towards developing various aspects of FPD's to improve its optical transmittance, mechanical stability, chemical stability etc. Graphene is increasingly been recognized as an excellent material for flexible photovoltaic devices because of its unique optical, electrical and mechanical properties. The prospects of introducing an inexpensive and abundant carbon-based material such as graphene in making flexible, low-cost, transparent PV cells cannot be over emphasized. However, the method to synthesize graphene to achieve the best performance is still complicated. This paper presents a brief overview of recent developments made in flexible photovoltaic devices using graphene.
\end{abstract}

Keywords: Graphene, Solar cell, Photovoltaic, Flexible devices, Efficiency.

\section{INTRODUCTION}

Fossil fuels are a major and cheap source of energy but have a negative impact on the environment [1-3]. Energy harnessed from the sun offers a renewable option compared to fossil sources [4]. Photovoltaic (PV) devices used to harvest solar energy are generally classified into three generations. The first generation is based on crystalline silicon wafers and often referred to as conventional photovoltaic cells. Subgroups in this generation are monocrystalline and polycrystalline silicon photovoltaic cells [5]. The second generation is commonly called thin-film photovoltaic cells because they are made of very thin layers that have been deposited a suitable substrate [5]. Subgroups here include amorphous silicon, cadmium telluride and copper-indium-gallium-selenide. The third generation includes a range of alternatives such as dye-sensitized (Gratzel cell), perovskite, quantum dot and organic solar cells [6-8], these offer a comparable low-cost option and have received tremendous attention in research activities over the last couple of decades [9]. Figure 1 is an illustration of the various generations of photovoltaic cells.

Flexible photovoltaic devices are mainly derived from second and third generation photovoltaic cells [7, $10,11]$. They are obtained by the use of flexible

*Address correspondence to this author at the Kansas Polymer Research Center, Pittsburg State University, Pittsburg, KS 66762, USA; Tel: +1 620 2354763; Fax: +1 620235 4003; E-mail: ramguptamsu@gmail.com substrates like polymer sheets, metal foils, plastic foils, and paper [12-17]. For human convenience, flexible electronics have been researched extensively over the past couple of decades. The importance of flexible photovoltaic devices (FPD's) cannot be over emphasized. They are light in weight, bendable, portable, wearable and can be installed easily. They can be used in electronic textiles, unmanned aerial vehicles, and integrated photovoltaic systems $[18,19]$. Substrates which are less expensive can be used in the production of flexible photovoltaic devices thereby reducing the cost of production [20,21]. Also, irregular shapes and sizes can be obtained due to their flexibility, for instance, curved photovoltaic cells and photovoltaic cells that can be rolled $[10,12,22]$. It is also reported that curved photovoltaic cells produced higher total electrical energy per surface area compared to flat photovoltaic cells [23]. Furthermore, more cost-effective processing methods and materials can be used in the manufacture of flexible photovoltaic devices $[17,24]$.

Talking about materials, new materials have been intensively studied for the last couple of decades as an alternative to conventional rigid materials used for photovoltaic devices [25-32]. Many researchers have focused on materials that can offer excellent electrical, optical, and mechanical properties suitable for designing photovoltaic flexible device [33-38]. As an alternative to the conventional rigid materials, graphene has drawn significant research, there are numerous 


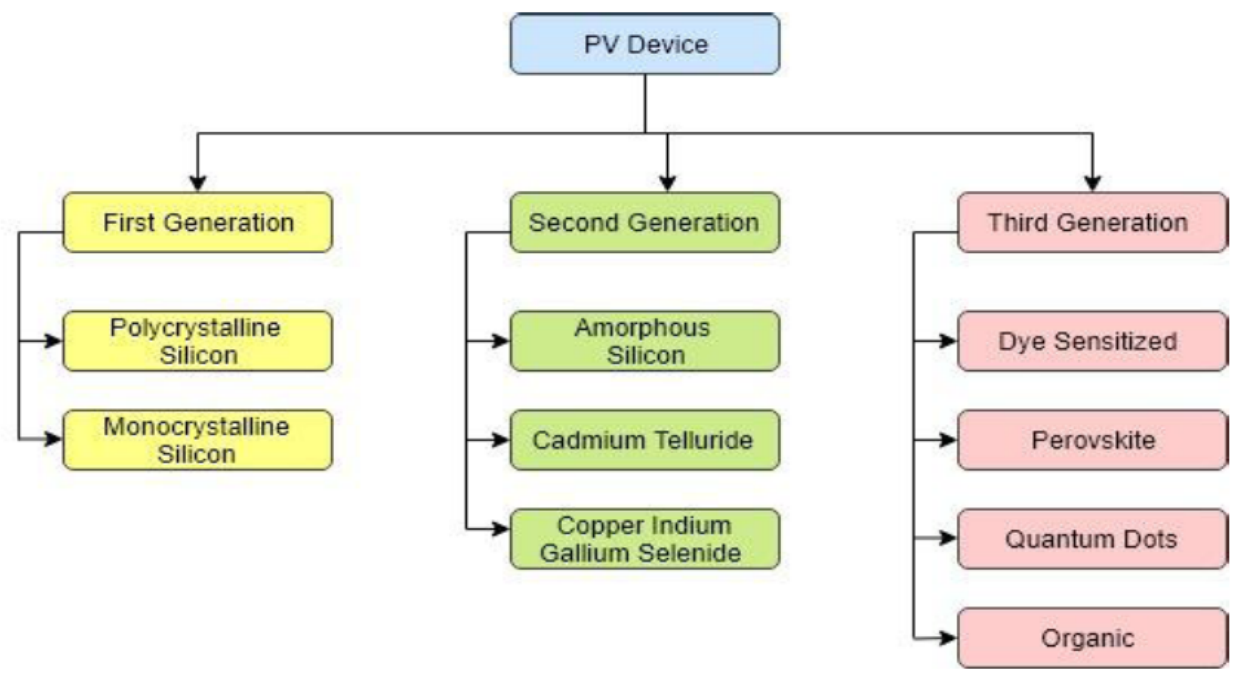

Figure 1: A chart showing the PV cell generations.

reports it has found uses as an electrode, electrolyte, transport layers etc. in various reports [21, 39, 40]. Graphene, a hexagonal array of $\mathrm{sp}^{2}$-hybridized atomic thick carbon sheets exhibits attractive properties, such as high electrical conductivity, high transparency and good mechanical flexibility [41-44]. Several reports in the literature have given credence to the suitability of graphene for the successful development of flexible optoelectronics, pointing to these properties. The study of the electrical mobility of single-layer graphene yielded approximately $10,000 \mathrm{~cm}^{2} \mathrm{~V}^{-1} \mathrm{~s}^{-1}$ at room temperature [45, 46]. Nair et al developed a model $(T=100-2.3 \mathrm{~N} \%)$ to estimate the optical transmittance of graphene layers, where $N$ represents the number of graphene layers [46]. Hence single-layer graphene is estimated to have a transmittance of $97.7 \%$. It is also reported to have a large surface area of $2,600 \mathrm{~m}^{2} / \mathrm{g}$ [47]. Li et al. measured both the elastic properties and intrinsic breaking strength of free-standing monolayer of graphene membranes by nanoindentation, they reported a breaking strength is $42 \mathrm{~N} / \mathrm{m}$ and Young's modulus of 1.0 TPa [44]. These unique properties have made it an outstanding option for the applications of flexible photovoltaic devices. This paper gives a brief overview of recent developments made in flexible photovoltaic devices using graphene.

\section{RECENT PROGRESS IN FLEXIBLE PV DEVICES}

Flexible electrodes are an essential component in the successful development of flexible PV devices. Shin et al. developed a flexible organic solar cell using doped-graphene layers as anode/cathode transparent conductive electrodes (TCEs) [48]. The device archived a power conversion efficiency of $3.12 \%$ and a $35.58 \%$ increase when $\mathrm{Al}$ reflective mirrors were added to the top and bottom side of the device. The device retained a remarkable $99 \%$ of the original PCE through bending test, exhibiting promising mechanical flexibility (Figure 2). The same group also achieved PCE of $3.66 \%$ by fabricating graphene transparent conducting electrodes doped with quantum dots (GQDs)-mixed silver nanowires (AgNWs) on polyethylene terephthalate substrates for highly-flexible organic solar cells (OSCs) [40]. Samples were prepared with varying GQD concentration from 0.01 to $0.03 \mathrm{~g} / \mathrm{L}$. The sample achieved PCE of 3.31 to $3.62 \%$. Samples prepared with GQDs-mixed Ag NWs/GR TCE/PET exhibited excellent mechanical flexibility, maintaining $90 \%$ of its PCE after 1000 cyclic bending test. However, samples without GQD showed significant degradation (60\%) during the bending testing, this was attributed to the breaking-off damage of the Ag NWs. Additionally, the devices were subjected to the humidity of $40 \%$ at $25{ }^{\circ} \mathrm{C}$ for 10 days, and the samples lost up to $14 \%$ PCE depending on the presence of GQDs.

Dong et al. fabricated a vertically aligned carbon nanotubes/graphene hybrid electrode as a TCO and Pt-free flexible cathode for dye-sensitized solar cells (DSSC) [49]. The PCE of the flexible DSSC with vertically aligned carbon nanotubes/graphene/Ni foil $(0.025 \mathrm{~mm})$ as the cathode achieved $3.9 \%$, while the sample with $\mathrm{Pt}$ cathode achieved a lower value of $3.4 \%$. Also, electrochemical impedance spectroscopy testing showed high electrocatalytic activity for the hybrid carbon system. In a different approach, Li et al. use CVD to grow vertically aligned carbon nanotubes (VACNTs) directly on a free-standing graphene paper (GP) to be utilized as the electrodes for lithium-ion batteries and dye-sensitized solar cells [15]. The 
(a)

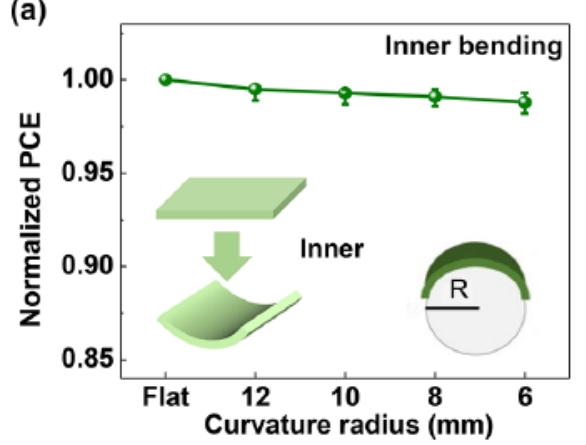

(b)

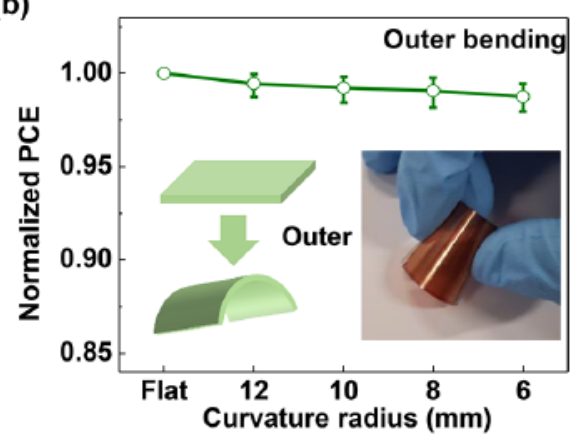

Figure 2: Changes of normalized PCEs as functions of bending cycles at $R=\infty, 12,10,8$, and 6 mm for FOSCs under (a) inner bending and (b) outer bending. The insets describe the bending tests and show a real image of a typical FOSC. "Reprinted (adapted) from ref. [48] with permission from American Chemical Society. Copyright (2018) American Chemical Society."

performance of the VACNT/GP film as a counter electrode in dye-sensitized solar cells (DSSCs) was investigated. They reported a PCE of $6.05 \%$ and $3.88 \%$ for samples prepared with vertically aligned carbon nanotubes/graphene film and tilted aligned carbon nanotubes/graphene film, respectively.

Yin et al have prepared a large scale single layer graphene (SLG) and multilayer graphene on a flexible plastic substrate PET through layer-by-layer (LBL) deposition method [50]. It was observed that the transmission and anti-bending performance based on PET/GE were superior to traditional PET/ITO with an improved power conversion efficiency of the dyesensitized solar cell (Figure 3). (DSC) using flexible PET/GE conductive substrate was comparable to that of the DSC using the PET/ITO substrate.

Park et al. demonstrated graphene-based flexible polymer solar cells on polyethylene naphthalate (PEN) substrates and investigated the mechanical flexibility under different conditions [51]. Their graphene anode/PEDOT:PSS/MoO ${ }_{3} / \mathrm{PTB} 7: \mathrm{PC} 71 \mathrm{BM} / \mathrm{Ca} / \mathrm{Al}$ and graphene cathode/ZnO/PTB7:PC71BM/MoO $/ \mathrm{Ag}$ polymer solar cells on PEN substrates achieved a remarkable PCE of $6.1 \%$ and $7.1 \%$ for anode and cathode configurations, respectively. These were comparable to devices with ITO. The high-power conversion efficiencies were attributed to the thermally treated $\mathrm{MoO}_{3}$ electron blocking layer and $\mathrm{ZnO}$ electron transport layer that was deposited on graphene. The device withstood consecutive flexing cycles at $5 \mathrm{~mm}$
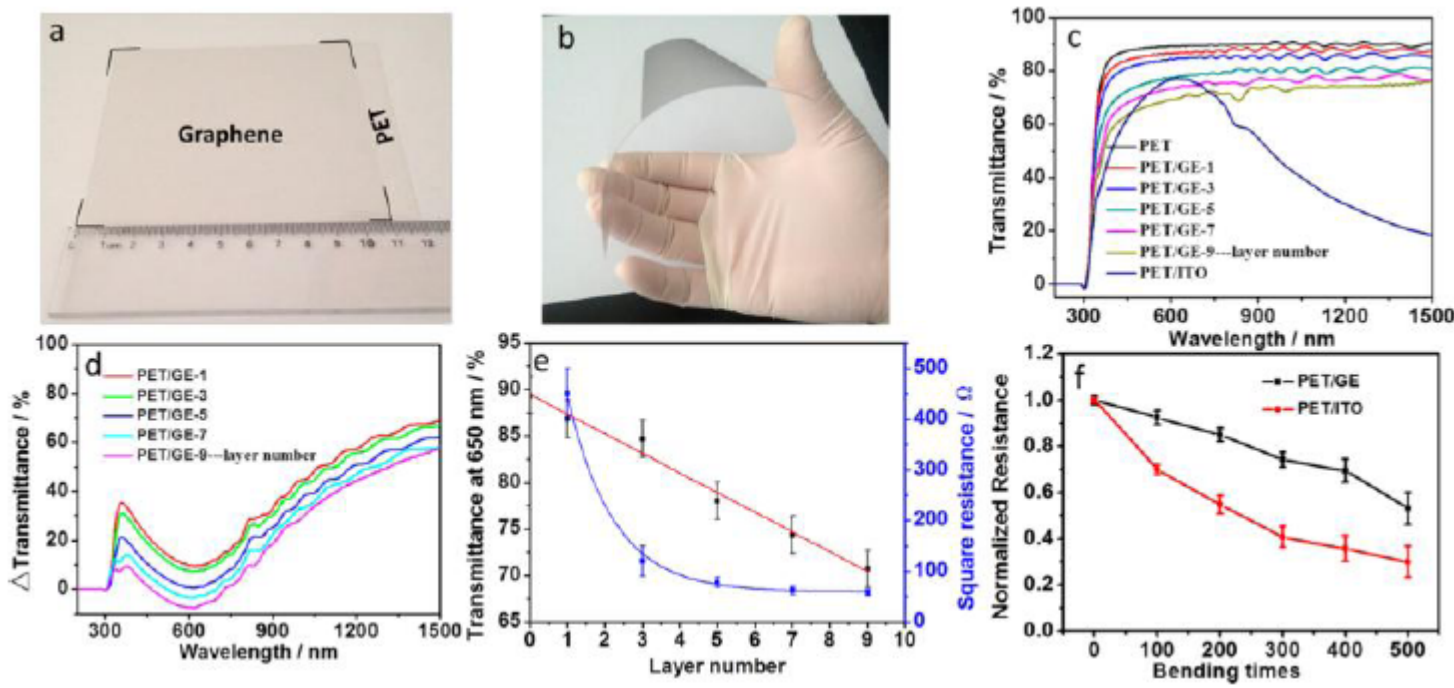

Figure 3: (a) Large-scale graphene on PET prepared by the thermal release adhesive transfer method (TRA-TM); (b) photograph of graphene on PET; (c) transmittance of different layers graphene on PET; (d) difference transmittance between different layers of graphene/PET and ITO/PET; (e) changes of transmittance and square resistance with layer number of graphene; (f) resistance variations after 500 cycles bending around $1 \mathrm{~cm}$ diameter. "Reprinted (adapted) from ref. [50] with permission from American Chemical Society. Copyright (2016) American Chemical Society." 
radius (corresponding to a strain of $\sim 4.3 \%$ ), maintaining its solar cell performance (Figure 4).

Heo et al. presented a method of adjusting the anodization reaction time of polished Ti-metal substrate and number of graphene layers deposited on PDMS
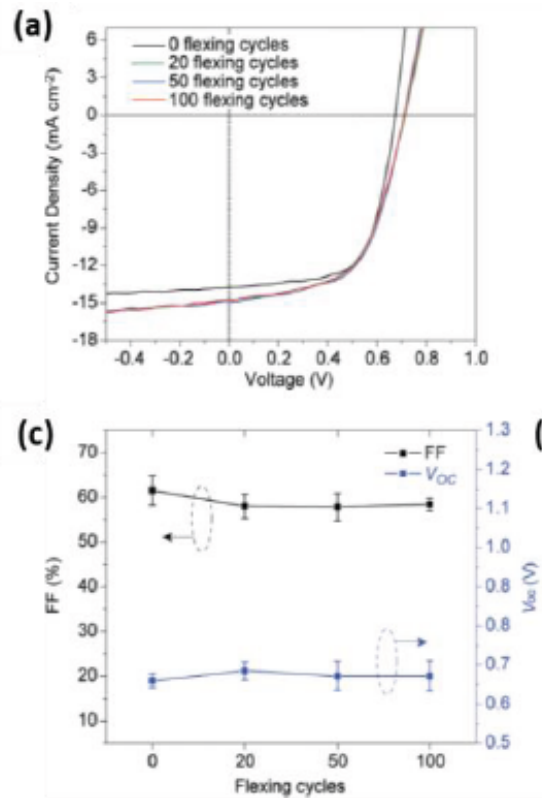

electrodes, to fabricate flexible $\mathrm{CH}_{3} \mathrm{NH}_{3} \mathrm{Pbl}_{3}$ (MAPbI3) organic-inorganic hybrid perovskite solar cells [52]. The fabricated device using polished $\mathrm{Ti}$ substrate/ $/ \mathrm{TiO}_{2}$ formed by anodization/MAPbl ${ }_{3}$ OHP/PTAA/graphene/PDMS achieved PCE $=15 \%$ (Figure 5). A single graphene layer exhibited carrier (b)

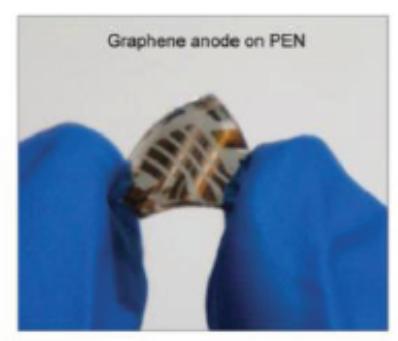

(d)

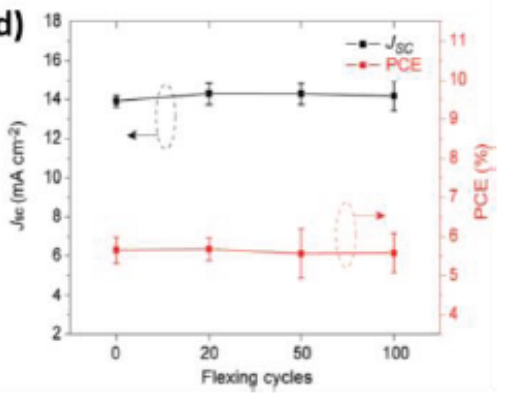

Figure 4: Graphene-based flexible PSCs on PEN. (c) AM1.5G J-V characteristics of the champion graphene devices before and after different flexing cycles, displaying no significant changes in the device performance after the mechanical deformation. (d) A digital photograph of a flexible graphene PSC. (e, f) Photovoltaic performance characteristics (JSC, VOC, FF, and PCE) of the devices displayed in (c). "Reprinted (adapted) from ref. [51] with permission from American Chemical Society. Copyright (2014) American Chemical Society."

(a)
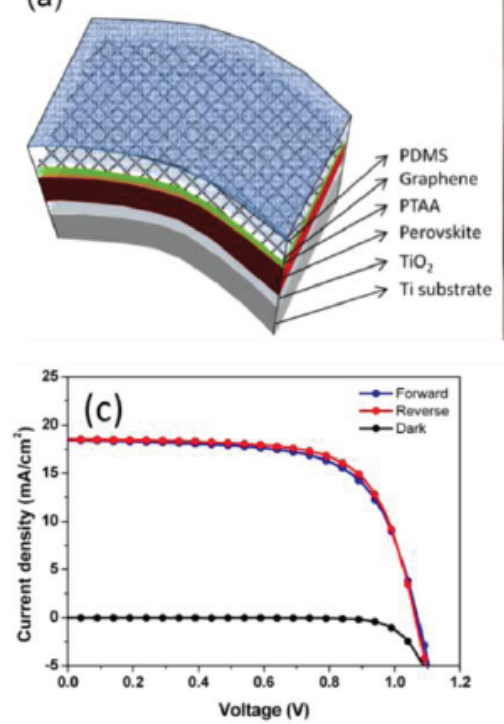
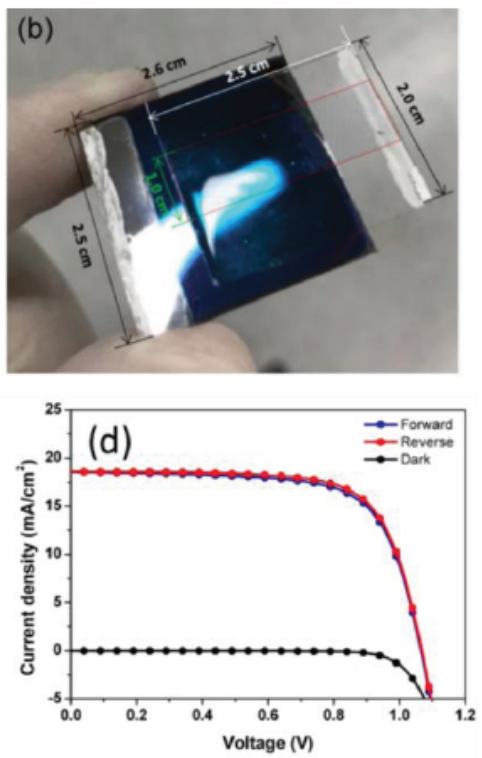

Figure 5: (a) Schematic device structure of the flexible MAPbI3 OHP solar cell, (b) photograph of the real device, (c-d) J-V (current density-voltage) curves of flexible MAPbI3 OHP solar cells formed on the polished Ti substrate with different anodization reaction times: (c) 30, and (d) 40. "Reprinted (adapted) from ref. [52] with permission from American Chemical Society. Copyright (2018) American Chemical Society." 

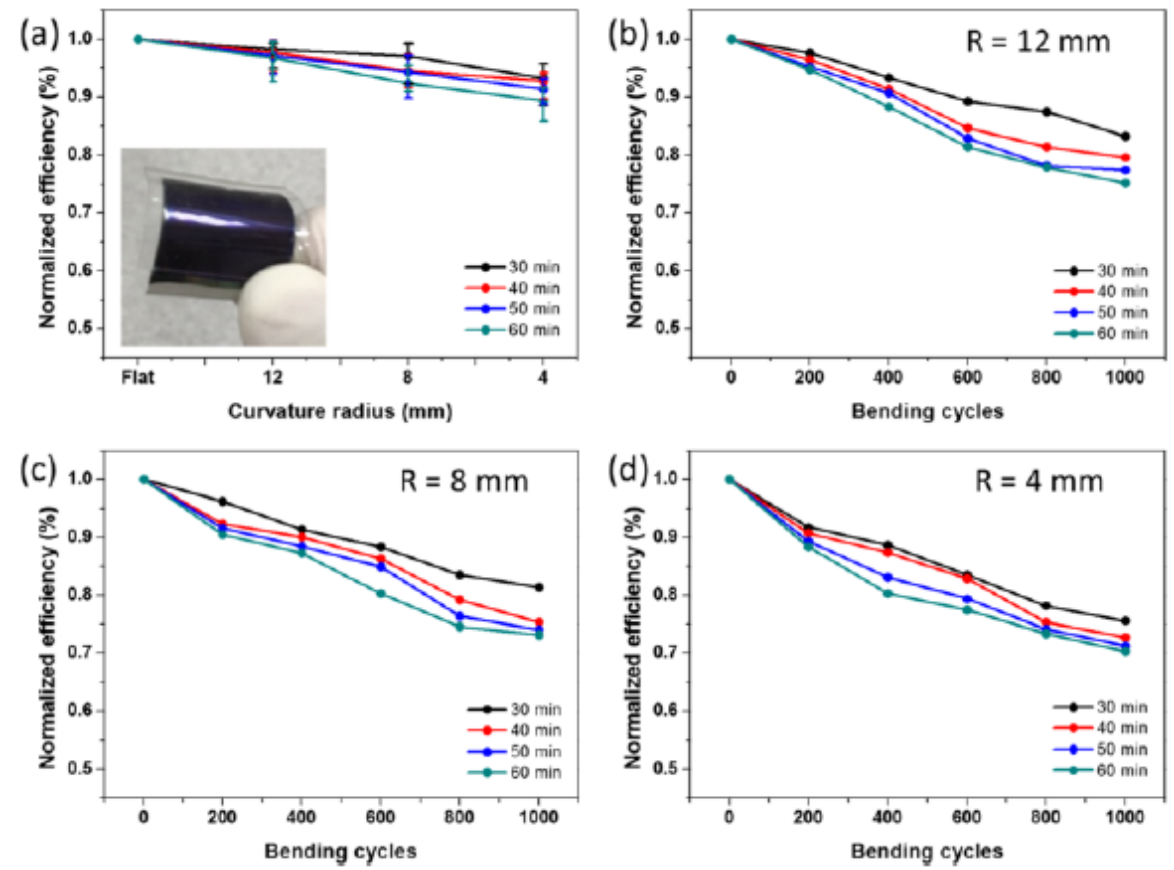

Figure 6: (a) Normalized efficiency of flexible MAPbI3 OHP solar cells formed on the anodized Ti substrates with curvature radius $(R)$ and $(\mathbf{b}-\mathbf{d})$ normalized efficiencies of flexible MAPbl3 OHP solar cells with respect to the bending cycles under different curvature radii: (b) $R=12$, (c) $R=8$, and (d) $R=4 \mathrm{~mm}$. "Reprinted (adapted) from ref. [52] with permission from American Chemical Society. Copyright (2018) American Chemical Society."

concentration, mobility and the work function of $2.1 \times$ $10^{18} \mathrm{~cm}^{-3}, 2053 \mathrm{~cm}^{2} \mathrm{~V}^{-1} \mathrm{~s}^{-1}$ and 4.58 , respectively. These values either increased/decreased monotonically as the number of graphene layer was increased to 4 . Also, the mechanical flexibility of the perovskite solar cells was investigated, Figure $\mathbf{6}$, shows that the performance is slightly degraded with respect to the radius of bending as the anodizing reaction time increases.

Zongyou Yin and his research group chemically reduced graphene oxide ( $\mathrm{rGO}$ ) and transferred it onto flexible polyethylene terephthalate (PET) substrates and then used as transparent and conductive electrodes for flexible organic photovoltaic (OPV) devices. The fabricated device [PEDOT:PSS/rGO/PET] achieved $\mathrm{PCE}=0.78 \%$, for the sample with $16 \mathrm{~nm}$ thickness, a sheet resistance of $3.2 \mathrm{k} \Omega / \mathrm{sq}$ and transmittance of $65 \%$ [53]. The sample sustained a thousand cycles of bending at a tensile strain of approximately $2.9 \%$. Jang et al. compared the PCE of semi-transparent flexible perovskite solar cells fabricated by doping of graphene (GR) with bis (trifluoromethane sulfonyl)-amide (TFSA) and triethylene tetramine (TETA) as with anode and cathode, respectively [54]. Samples were fabricated using laminating stacks of PET/TETAGR/ZnO/MAPbI 3 /PTAA and the PEDOT:PSS/TFSA-
GR/PET. PCE of PCEs of 10.96(11.06)/11.16(11.22)\% were achieved by illumination at the TFSA-GR/TETAGR sides. The device maintained $70 \%$ of initial PCE after 1000 bending cycles at $\mathrm{R}=8 \mathrm{~mm}$. Liu et al. also demonstrated for the first time ultrathin flexible perovskite solar cells with graphene transparent electrodes prepared on flexible PET substrates, they achieved PCE $=11.5 \%$ and output power per unit weight of $5.07 \mathrm{w} / \mathrm{g}$ [55]. Device characterization showed little degradation during bending testing test. In another approach, computational methods were used to optimize the design of flexible organic solar cells with graphene/PEDOT:PSS Schottky junction on PET substrates. The optimized device exhibited excellent photovoltaic characterization under AM1.5 G illumination $\left(\mathrm{V}_{\mathrm{oc}}=0.68 \mathrm{~V}, \mathrm{~J}_{\mathrm{sc}}=0.68 \mathrm{~mA} / \mathrm{cm}^{2}, \mathrm{FF}=60.34 \%\right.$, $\eta=2.87 \%$ ) [56]. Gomez De Arco et al. implemented a continuous, highly flexible, and transparent graphene films obtained by chemical vapor deposition (CVD) as transparent conductive electrodes (TCE) in organic photovoltaic cells [57]. CVD based graphene electrode achieved PCE of $1.18 \%$ (Figure 7 ), which is slightly lower than PCE of the device based on ITO $(P C E=1.27 \%)$. However, they observed that the performance of both devices (CVD graphene electrodes, ITO cells) was slightly degraded upon bending. 


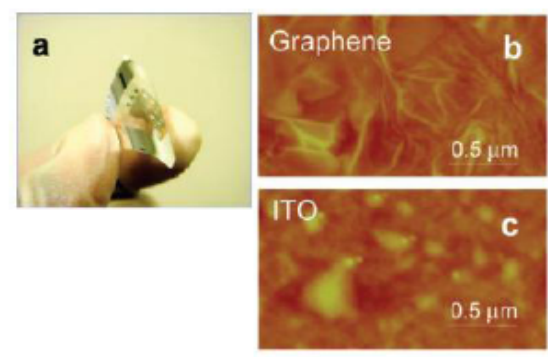

e

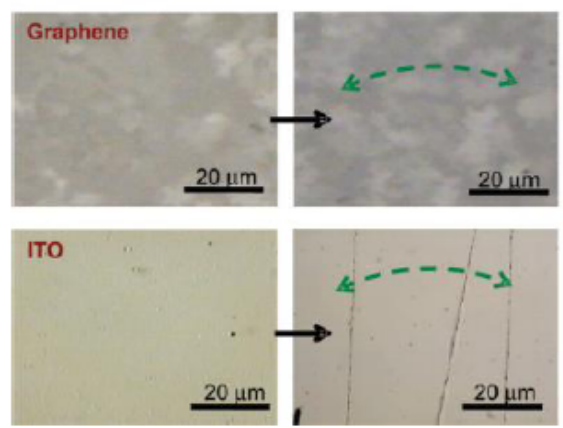

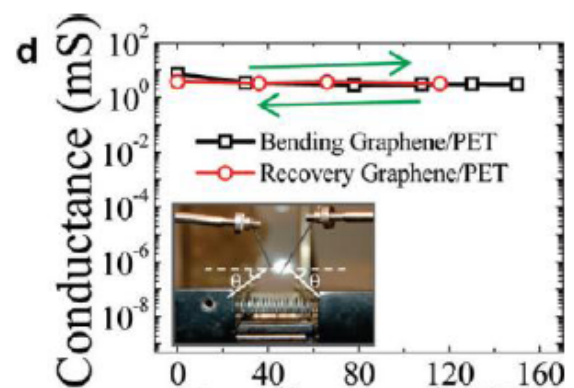

$f$
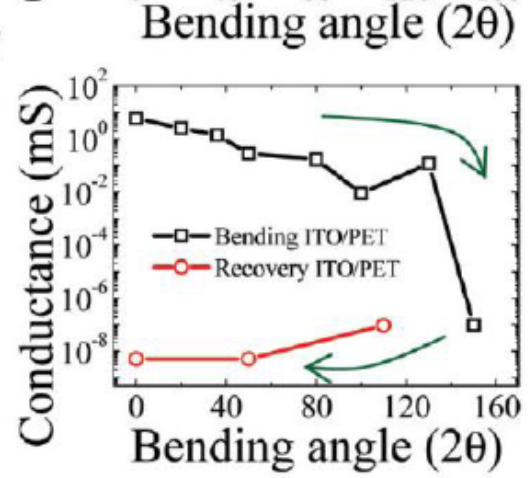

Figure 7: (a) Photograph illustrating high flexibility of CVD graphene transferred on a PET flexible substrate. (b, c) AFM images of the surface of CVD graphene and ITO films on PET, respectively. (d, f) Conductance of the CVD graphene and ITO films on PET substrates under bending conditions, respectively. The devices used to monitor the conductance had channel width $(W)=1$ $\mathrm{mm}$ and length $(L)=1 \mathrm{~mm}$. (e) Optical images of CVD graphene (top) and ITO (bottom) films on PET before and after being bent at the angles specified in panels $b$ and $c$. Arrows show the direction of the bending. "Reprinted (adapted) from Ref [57] with permission from American Chemical Society. Copyright (2010) American Chemical Society."

Graphene has been widely reported as an effective transport layer. Organic PV cell with hybrid Graphene$\mathrm{MoO}_{3}\left(\mathrm{G}-\mathrm{MoO}_{3}\right)$ particles as hole transport layers (HTLs) was studied by Dong et al. using a solution process method [58]. Another PV cell with the only $\mathrm{MoO}_{3}$ as $\mathrm{HTLs}$ was fabricated for comparison. A PCE of $7.072 \% \quad\left(\mathrm{~V}_{\mathrm{oc}}=0.864 \mathrm{~V}, \quad \mathrm{~J}_{\mathrm{sc}}=12.829 \mathrm{~mA} / \mathrm{cm}^{2}\right)$ was observed for the device with $\mathrm{G}-\mathrm{MoO}_{3} \mathrm{HTL}$, a $19 \%$ increase compared to the sample without Graphene. The $\mathrm{G}-\mathrm{MoO}_{3}$ device also exhibited higher optical transmittance, improved electrical conductivity, and enhanced hole mobility. Sim et al. worked on $\mathrm{Cu}$ (In, $\mathrm{Ga}) \mathrm{Se}_{2}$ (CIGS) flexible PV cells and used graphene as the hole transport layer [21]. CIGS solar cells were fabricated on graphene film deposited on flexible $\mathrm{Cu}$ foil using a chemical vapor deposition process. For comparison, a Mo/stainless steel substrate was used to fabricate a CIGS PV cell. Raman spectrum of the graphene film showed high-quality crystalline graphene monolayers were obtained and evenly distributed on the $\mathrm{Cu}$ foil. A PCE of $9.91 \%$ (40\% increase compared to the reference CIGS/Mo/STS sample) with short circuit current density of $28.84 \mathrm{~mA} / \mathrm{cm}^{2}$, open circuit voltage of $0.531 \mathrm{~V}$ and fill factor of $64.75 \%$ was obtained for the graphene hole transport layer PV cell
(Figure 8). The high PCE was attributed to the high open circuit voltage and large fill factor. A new way to produce a low-cost and solution-processed $\mathrm{GO}$ and RGO atomic-thick films were used as hole-selective layers (HSL) to boost the efficiency and durability of rrP3HT:PCBM-based photocathodes on ITO-PET substrates; the method entails spin coating of RGO dispersed in ethanol, spin cast of $\mathrm{TiO}_{2}$ and $\mathrm{Pt} / \mathrm{C}$ Nafion blend on ITO-PET substrates. The prepared photocathode $\left(9 \mathrm{~cm}^{2}\right.$ area) achieved a remarkable cathodic $\mathrm{J}_{0} \mathrm{~V}$ vs RHE $=2.8 \mathrm{~mA} / \mathrm{cm}, \mathrm{V}_{\mathrm{o}}=0.45 \mathrm{~V}$ vs RHE, and $\varphi$ saved of $0.31 \%$ [59]. This performance was attributed to the presence of HSL materials which has been modified with GO/RGO [60].

Graphene has also found use in electrolytes for photovoltaic applications. As reported by Akhar and his research group, novel composite electrolytes were prepared by combining 2D graphene (Gra) and polyethylene oxide (PEO) as a solid electrolyte for dyesensitized solar cells (DSSCs) [61]. The optimized $0.5 \%$ Gra-PEO composite electrolyte exhibited a higher ionic conductivity of $3.32 \mathrm{mS} / \mathrm{cm}$, while the fabricated cells exhibited high overall conversion efficiency of $5.23 \%\left(\mathrm{~V}_{\mathrm{oc}}=0.592 \mathrm{~V}, \mathrm{~J}_{\mathrm{sc}}=18.32 \mathrm{~mA} / \mathrm{cm}^{2}\right.$, 

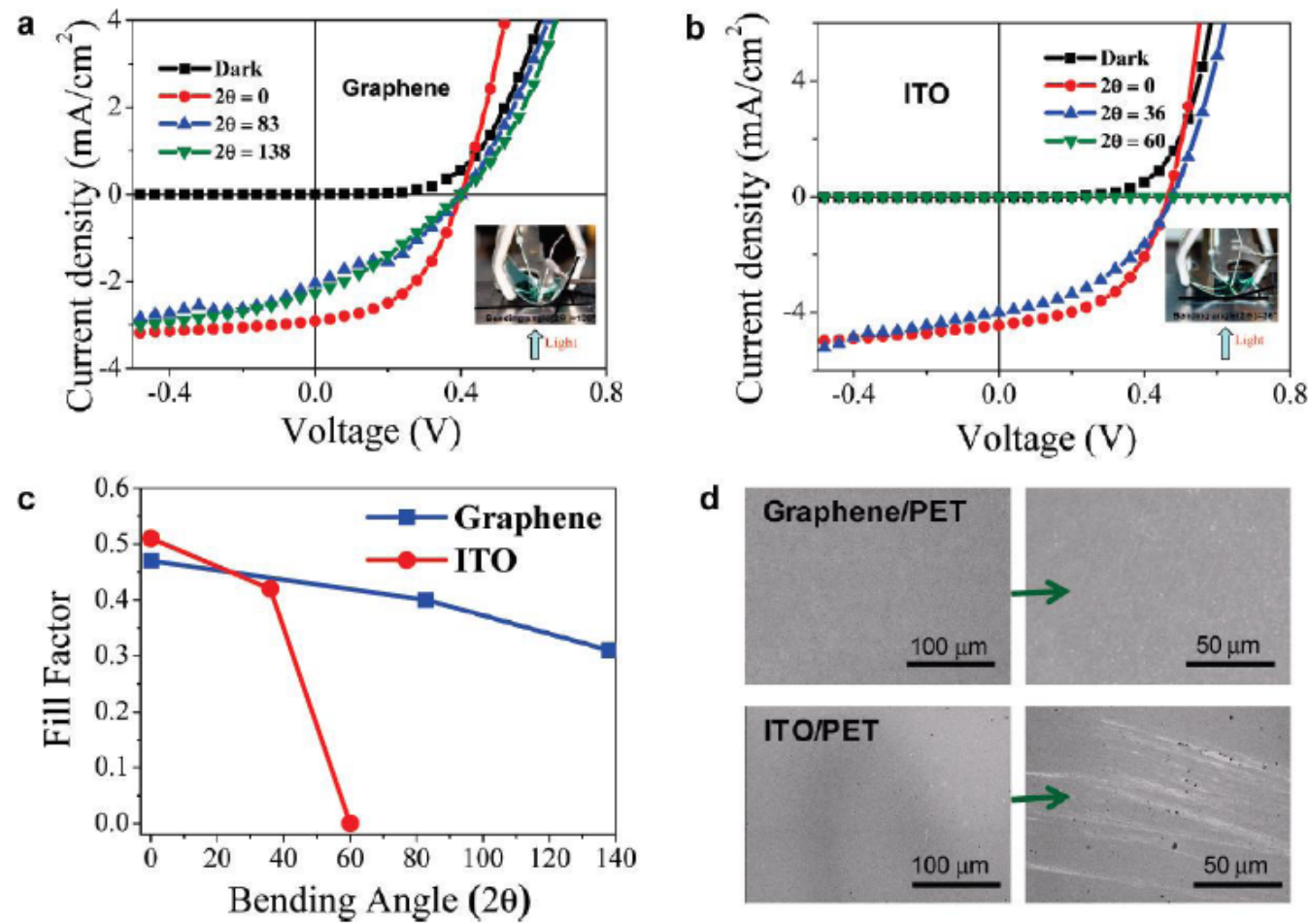

Figure 8: Current density vs voltage characteristics of CVD graphene (a) or ITO (b) photovoltaic cells under $100 \mathrm{~mW} / \mathrm{cm} 2$ AM1.5G spectral illumination for different bending angles. Insets show the experimental setup employed in the experiments. (c) Fill factor dependence of the bending angle for CVD graphene and ITO devices. (d) SEM images showing the surface structure of CVD graphene (top) and ITO (bottom) photovoltaic cells after being subjected to the bending angles described in panels a and b. "Reprinted (adapted) from Ref [57] with permission from American Chemical Society. Copyright (2010) American Chemical Society."

$\mathrm{FF}=0.48)$. The enhanced photovoltaic performance was attributed to the large-scale formation of the iodide couple in the redox electrolyte and relatively high ionic conductivity.

\section{CONCLUSION AND FUTURE REMARKS}

In this brief review, we have summarized the recent progress in the development of novel graphene-based flexible photovoltaic devices. Clearly Graphene present obvious advantages over conventional photovoltaic materials. Flexible solar cells based on graphene including dye-sensitized solar cells, organic solar cells and perovskite solar cells etc., have been reviewed. The role of graphene was reviewed as to its utilizing as an electrode (anode, cathode), electrolyte and transport layers. Furthermore, the role of graphene in flexible photovoltaic devices is also briefly discussed, for example, the incorporation of graphene in solar cells in most cases improved the power conversion efficiency of photovoltaic devices, enhancing the performance. Although great progress has been made in the integration of graphene in flexible photovoltaic cells, flexible solar cells still have a long way to make it to the main stream industrial manufacturing. Further development of graphene-based flexible photovoltaic devices would involve an in-depth knowledge of (1) the synthesis of high-quality defect-free graphene and (2) a more efficient way of transferring graphene to the substrate substrates to avoid creases and defects. Further developments dopants for graphene, can go a long way to improve properties such as electrical conductivity and work function while maintaining its inherent unique properties. It is envisaged that the discovery of new materials and technologies will power the next generation of research on graphene in flexible PV devices, in terms of photosensitizers, electrodes, electrolyte and transport layers so as to further improve the performance and make these devices commercially viable.

\section{ACKNOWLEDGEMENTS}

Dr. Ram K. Gupta expresses his sincere acknowledgment to the Polymer Chemistry Initiative, Pittsburg State University for providing financial and research support. 


\section{REFERENCE}

[1] VS. Ediger, An integrated review and analysis of multienergy transition from fossil fuels to renewables, Energy Procedia. 156 (2019) 2-6.

https://doi.org/10.1016/j.egypro.2018.11.073

[2] T. Kåberger, Progress of renewable electricity replacing fossil fuels, Glob. Energy Interconnect. 1 (2018) 48-52. doi:https://doi.org/10.14171/j.2096-5117.gei.2018.01.006.

[3] F. Martins, C. Felgueiras, M. Smitková, Fossil fuel energy consumption in European countries, Energy Procedia. 153 (2018) 107-111. https://doi.org/10.1016/j.egypro.2018.10.050

[4] M. Ram, M. Child, A. Aghahosseini, D. Bogdanov, A. Lohrmann, C. Breyer, A comparative analysis of electricity generation costs from renewable, fossil fuel and nuclear sources in G20 countries for the period 2015-2030, J. Clean. Prod. 199 (2018) 687-704. https://doi.org/10.1016/j.jclepro.2018.07.159

[5] B. Kramer, Advances in Solid State Physics, Springer, Berlin, Heidelberg, 2004 https://doi.org/10.1007/b95888

[6] A. Mohammad Bagher, Types of Solar Cells and Application, Am. J. Opt. Photonics. 3 (2016) 94. https://doi.org/10.11648/j.ajop.20150305.17

[7] A. Cristobal, Ana, Martí Vega, Antonio, Luque López, Next Generation of Photovoltaics, 2012. https://doi.org/10.1007/978-3-642-23369-2

[8] K. Ranabhat, L. Patrikeev, AA. evna Revina, K. Andrianov, V. Lapshinsky, E. Sofronova, An introduction to solar cell technology, J. Appl. Eng. Sci. 14 (2016) 481-491. https://doi.org/10.5937/jaes14-10879

[9] AW. Gavin J. Conibeer, Solar Cell Materials: Developing Technologies, 2014 WILEY-VCH Verlag GmbH \& Co. KGaA, Weinheim, 2014 https://doi.org/10.1002/ente.201405007

[10] M. Bojic, J. Radulovic, V. Rankovic, D. Nikolic, L. Bojic, J. Skerlic, Flexible Thin-Film Solar photovoltaics: research and application, Ann. Fac. Eng. Hunedoara - Int. J. Eng. 14 (2016)

$37-40$. http://library.pittstate.edu:2048/login?url=https://search.ebsco host.com/login.aspx?direct=true\&AuthType $=i p \& d b=a p h \& A N=$ 113730823\&site=ehost-live.

[11] G. Li, L. Sheng, T. Li, J. Hu, P. Li, K. Wang, Engineering flexible dye-sensitized solar cells for portable electronics, Sol. Energy. 177 (2019) 80-98. https://doi.org/10.1016/j.solener.2018.11.017

[12] X. Fu, L. Xu, J. Li, X. Sun, H. Peng, Flexible solar cells based on carbon nanomaterials, Carbon N. Y. 139 (2018) 10631073.

https://doi.org/10.1016/j.carbon.2018.08.017

[13] M. Kaltenbrunner, MS. White, ED. Głowacki, T. Sekitani, T. Someya, NS. Sariciftci, S. Bauer, Ultrathin and lightweight organic solar cells with high flexibility, Nat. Commun. 3 (2012) 770

https://doi.org/10.1038/ncomms1772

[14] VK. Kapur, A. Bansal, P. Le, OI. Asensio, Non-vacuum processing of Culn1-xGaxSe2 solar cells on rigid and flexible substrates using nanoparticle precursor inks, Thin Solid Films. 431-432 (2003) 53-57. https://doi.org/10.1016/S0040-6090(03)00253-0

[15] S. Li, Y. Luo, W. Lv, W. Yu, S. Wu, P. Hou, Q. Yang, Q. Meng, C. Liu, H.-M. Cheng, Vertically Aligned Carbon Nanotubes Grown on Graphene Paper as Electrodes in Lithium-lon Batteries and Dye-Sensitized Solar Cells, Adv. Energy Mater. 1 (2011) 486-490. https://doi.org/10.1002/aenm.201100001

[16] X. Mathew, JP. Enriquez, A. Romeo, AN. Tiwari, CdTe/CdS solar cells on flexible substrates, Sol. Energy. 77 (2004) 831-
838.

https://doi.org/10.1016/j.solener.2004.06.020

[17] W. Zi, Z. Jin, S. Liu, B. Xu, Flexible perovskite solar cells based on green, continuous roll-to-roll printing technology, J. Energy Chem. 27 (2018) 971-989.

https://doi.org/10.1016/j.jechem.2018.01.027

[18] AJ. Baca, KJ. Yu, J. Xiao, S. Wang, J. Yoon, JH. Ryu, D. Stevenson, R.G. Nuzzo, A.A. Rockett, Y. Huang, J.A Rogers, Compact monocrystalline silicon solar modules with high voltage outputs and mechanically flexible designs, Energy Environ. Sci. 3 (2010) 208-211. https://doi.org/10.1039/b920862c

[19] DJ. Lipomi, Z. Bao, Stretchable, elastic materials and devices for solar energy conversion, Energy Environ. Sci. 4 (2011) 3314-3328.

https://doi.org/10.1039/c1ee01881g

[20] L. Li, S. Zhang, Z. Yang, EES. Berthold, W. Chen, Recent advances of flexible perovskite solar cells, J. Energy Chem 27 (2018) 673-689. https://doi.org/10.1016/j.jechem.2018.01.003

[21] JK. Sim, S. Kang, R. Nandi, JY. Jo, KU. Jeong, CR. Lee Implementation of graphene as hole transport electrode in flexible CIGS solar cells fabricated on $\mathrm{Cu}$ foil, Sol. Energy. 162 (2018) 357-363 https://doi.org/10.1016/j.solener.2018.01.053

[22] M. Pagliaro, R. Ciriminna, G. Palmisano, Flexible Solar Cells ChemSusChem. 1 (2008) 880-891. https://doi.org/10.1002/cssc.200800127

[23] V. Zardetto, G. Mincuzzi, F. De Rossi, F. Di Giacomo, A Reale, A. Di Carlo, T.M. Brown, Outdoor and diurnal performance of large conformal flexible metal/plastic dye solar cells, Appl. Energy. 113 (2014) 1155-1161. https://doi.org/10.1016/j.apenergy.2013.08.056

[24] K. Sun, F. Liu, J. Huang, C. Yan, N. Song, H. Sun, C. Xue, Y. Zhang, A. Pu, Y. Shen, J.A. Stride, M. Green, X. Hao, Flexible kesterite Cu2ZnSnS4 solar cells with sodium-doped molybdenum back contacts on stainless steel substrates, Sol. Energy Mater. Sol. Cells. 182 (2018) 14-20. https://doi.org/10.1016/j.solmat.2018.02.036

[25] M. Aleksandrova, N. Kurtev, V. Videkov, S. Tzanova, S Schintke, Material alternative to ITO for transparent conductive electrode in flexible display and photovoltaic devices, Microelectron. Eng. 145 (2015) 112-116. https://doi.org/10.1016/j.mee.2015.03.053

[26] N. Bednar, A. Caviasca, P. Sevela, N. Severino, N. Adamovic, Modelling of flexible thin-film modules for building and product integrated photovoltaics, Sol. Energy Mater. Sol. Cells. 181 (2018) 38-45. https://doi.org/10.1016/j.solmat.2017.12.035

[27] S. Hou, Fiber Solar Cells, Springer Singapore, 2017. https://doi.org/10.1007/978-981-10-2864-9

[28] T. Jayenta Singh, S. Singh, S. Masiul Islam, R. Get, P. Mahala, K. Jolson Singh, Flexible organic solar cells with graphene/PEDOT:PSS Schottky junction on PET substrates, Optik (Stuttg). 181 (2019) 984-992. https://doi.org/10.1016/j.ijleo.2018.12.179

[29] BR. Lee, JS. Goo, YW. Kim, YJ. You, H. Kim, SK. Lee, JW. Shim, TG. Kim, Highly efficient flexible organic photovoltaics using quasi-amorphous $\mathrm{ZnO} / \mathrm{Ag} / \mathrm{ZnO}$ transparent electrodes for indoor applications, J. Power Sources. 417 (2019) 61-69. https://doi.org/10.1016/j.jpowsour.2019.02.015

[30] RN. Paranthaman, M. Parans, Wong-Ng, Winnie, Bhattacharya, Semiconductor Materials for Solar Photovoltaic Cells, Springer International Publishing, 2016. https://doi.org/10.1007/978-3-319-20331-7

[31] Y. Park, L. Bormann, L. Müller-Meskamp, K. Vandewal, K. Leo, Efficient flexible organic photovoltaics using silver nanowires and polymer based transparent electrodes, Org. 
Electron. 36 (2016) 68-72.

https://doi.org/10.1016/j.orgel.2016.05.032

[32] Sergio Pizzini, Advanced Silicon Materials for Photovoltaic Applications, John Wiley \& Sons, Inc., 2012. https://doi.org/10.1002/9781118312193

[33] ZF. GUOZHEN SHEN, Flexible Electronics: From Materials To Devices, World Scientific Publishing Company, 2016. https://doi.org/10.1142/9493

[34] K. Lim, S. Jung, JK. Kim, JW. Kang, JH. Kim, SH. Choa, DG. Kim, Flexible PEDOT: PSS/ITO hybrid transparent conducting electrode for organic photovoltaics, Sol. Energy Mater. Sol. Cells. 115 (2013) 71-78 https://doi.org/10.1016/j.solmat.2013.03.028

[35] B. Paci, G. Kakavelakis, A. Generosi, J. Wright, C. Ferrero, E. Stratakis, E. Kymakis, Improving stability of organic devices: a time/space resolved structural monitoring approach applied to plasmonic photovoltaics, Sol. Energy Mater. Sol. Cells. 159 (2017) 617-624 https://doi.org/10.1016/j.solmat.2016.01.003

[36] S. Roy, P. Bermel, Electronic and optical properties of ultrathin 2D tungsten disulfide for photovoltaic applications, Sol. Energy Mater. Sol. Cells. 174 (2018) 370-379. https://doi.org/10.1016/j.solmat.2017.09.011

[37] D. Shahrjerdi, S.W. Bedell, A. Khakifirooz, K. Cheng, Mechanically flexible nanoscale silicon integrated circuits powered by photovoltaic energy harvesters, Solid. State. Electron. 117 (2016) 117-122. https://doi.org/10.1016/j.sse.2015.11.023

[38] NSS. Sam-Shajing Sun, Organic Photovoltaics: Mechanisms, Materials, and Devices, CRC Press, 2017.

[39] WC. Oh, S. Chanthai, Y. Areerob, Novel flexible Ag nanoparticles doped on graphene - Ba2GalnO6 as cathode material for enhancement in the power conversion of DSSCs, Sol. Energy. 180 (2019) 510-518.

https://doi.org/10.1016/j.solener.2019.01.033

[40] DH. Shin, SW. Seo, JM. Kim, HS. Lee, SH. Choi, Graphene transparent conductive electrodes doped with graphene quantum dots-mixed silver nanowires for highly-flexible organic solar cells, J. Alloys Compd. 744 (2018) 1-6. https://doi.org/10.1016/j.jallcom.2018.02.069

[41] JH. Ahn, BH. Hong, Graphene for displays that bend, Nat. Nanotechnol. 9 (2014) 737.

https://doi.org/10.1038/nnano.2014.226

[42] F. Bonaccorso, Z. Sun, T. Hasan, AC. Ferrari, Graphene photonics and optoelectronics, Nat. Photonics. 4 (2010) 611. https://doi.org/10.1038/nphoton.2010.186

[43] C. Lee, X. Wei, JW. Kysar, J. Hone, Measurement of the Elastic Properties and Intrinsic Strength of Monolayer Graphene, Science (80). 321 (2008) 385 LP-388. https://doi.org/10.1126/science.1157996

[44] X. Li, Y. Zhu, W. Cai, M. Borysiak, B. Han, D. Chen, RD. Piner, L. Colombo, RS. Ruoff, Transfer of Large-Area Graphene Films for High-Performance Transparent Conductive Electrodes, Nano Lett. 9 (2009) 4359-4363. https://doi.org/10.1021/n1902623y

[45] KS. Novoselov, AK. Geim, SV Morozov, D. Jiang, Y. Zhang, SV Dubonos, IV Grigorieva, AA. Firsov, Electric field in atomically thin carbon films, Science (80). 306 (2004) 666. https://doi.org/10.1126/science.1102896

[46] RR. Nair, P. Blake, AN. Grigorenko, KS. Novoselov, TJ. Booth, T. Stauber, NMR. Peres, AK. Geim, Fine Structure Constant Defines Visual Transparency of Graphene, Science (80). 320 (2008) 1308 LP-1308. https://doi.org/10.1126/science.1156965

[47] YH. Hu, H. Wang, B. Hu, Thinnest Two-Dimensional Nanomaterial-Graphene for Solar Energy, Chem Sus Chem. 3 (2010) 782-796. https://doi.org/10.1002/cssc.201000061
[48] DH. Shin, CW. Jang, HS. Lee, SW. Seo, SH. Choi, Semitransparent Flexible Organic Solar Cells Employing Doped-Graphene Layers as Anode and Cathode Electrodes, ACS Appl. Mater. Interfaces. 10 (2018) 3596-3601. https://doi.org/10.1021/acsami.7b16730

[49] P. Dong, Y. Zhu, J. Zhang, F. Hao, J. Wu, S. Lei, H. Lin, RH. Hauge, JM. Tour, J. Lou, Vertically Aligned Carbon Nanotubes/Graphene Hybrid Electrode as a TCO- and PtFree Flexible Cathode for Application in Solar Cells, J. Mater. Chem. A. 2 (2014) 20902-20907. https://doi.org/10.1039/C4TA05264A

[50] J. Yin, H. Zhou, Z. Liu, Z. Nie, Y. Li, X. Qi, B. Chen, Y. Zhang, $X$. Zhang, Indium- and Platinum-Free Counter Electrode for Green Mesoscopic Photovoltaics through Graphene Electrode and Graphene Composite Catalysts: Interfacial Compatibility, ACS Appl. Mater. Interfaces. 8 (2016) 5314-5319.

https://doi.org/10.1039/C4TA05264A

[51] H. Park, S. Chang, X. Zhou, J. Kong, T. Palacios, S. Gradečak, Flexible Graphene Electrode-Based Organic Photovoltaics with Record-High Efficiency, Nano Lett. 14 (2014) 5148-5154.

https://doi.org/10.1021/nl501981f

[52] JH. Heo, DH. Shin, ML. Lee, MG. Kang, SH. Im, Efficient Organic-Inorganic Hybrid Flexible Perovskite Solar Cells Prepared by Lamination of Polytriarylamine/CH3NH3Pb/3/Anodized Ti Metal Substrate and Graphene/PDMS Transparent Electrode Substrate, ACS Appl. Mater. Interfaces. 10 (2018) 31413-31421. https://doi.org/10.1021/acsami.8b11411

[53] Z. Yin, S. Sun, T. Salim, S. Wu, X. Huang, Q. He, YM. Lam, H. Zhang, Organic Photovoltaic Devices Using Highly Flexible Reduced Graphene Oxide Films as Transparent Electrodes, ACS Nano. 4 (2010) 5263-5268. https://doi.org/10.1021/nn1015874

[54] CW. Jang, JM. Kim, SH. Choi, Lamination-produced semitransparent/flexible perovskite solar cells with dopedgraphene anode and cathode, J. Alloys Compd. 775 (2019) 905-911. https://doi.org/10.1016/j.jallcom.2018.10.190

[55] Z. Liu, P. You, C. Xie, G. Tang, F. Yan, Ultrathin and flexible perovskite solar cells with graphene transparent electrodes, Nano Energy. 28 (2016) 151-157 https://doi.org/10.1016/j.nanoen.2016.08.038.

[56] TJ. Singh, S. Singh, SM. Islam, R. Get, P. Mahala, KJ. Singh, Flexible organic solar cells with graphene/PEDOT:PSS Schottky junction on PET substrates, Optik (Stuttg). 181 (2019) 984-992. https://doi.org/10.1016/j.ijleo.2018.12.179

[57] L. Gomez De Arco, Y. Zhang, CW. Schlenker, K. Ryu, ME. Thompson, C. Zhou, Continuous, Highly Flexible, and Transparent Graphene Films by Chemical Vapor Deposition for Organic Photovoltaics, ACS Nano. 4 (2010) 2865-2873. https://doi.org/10.1021/nn901587x

[58] Y. Dang, Y. Wang, S. Shen, S. Huang, X. Qu, Y. Pang, SRP. Silva, B. Kang, G. Lu, Solution processed hybrid Graphene$\mathrm{MoO} 3$ hole transport layers for improved performance of organic solar cells, Org. Electron. 67 (2019) 95-100. https://doi.org/10.1016/j.orgel.2019.01.013

[59] S. Bellani, L. Najafi, B. Martín-García, A. Ansaldo, AE. Del Rio Castillo, M. Prato, I. Moreels, F. Bonaccorso, GrapheneBased Hole-Selective Layers for High-Efficiency, SolutionProcessed, Large-Area, Flexible, Hydrogen-Evolving Organic Photocathodes, J. Phys. Chem. C. 121 (2017) 21887-21903. https://doi.org/10.1021/acs.jpcc.7b05904

[60] A. Guerrero, M. Haro, S. Bellani, MR. Antognazza, L. Meda S. Gimenez, J. Bisquert, Organic photoelectrochemical cells with quantitative photocarrier conversion, Energy Environ. Sci. 7 (2014) 3666-3673. https://doi.org/10.1039/C4EE01775G. 
[61] MS. Akhtar, S. Kwon, FJ. Stadler, OB. Yang, High efficiency solid state dye sensitized solar cells with graphenepolyethylene oxide composite electrolytes, Nanoscale. 5
(2013) 5403-5411.

https://doi.org/10.1039/c3nr00390f

Received on 6-3-2019

Accepted on 13-3-2019

Published on 13-3-2019

DOI: http://dx.doi.org/10.31875/2410-2199.2019.06.2

(C) 2019 Mensah-Darkwa et al.; Zeal Press.

This is an open access article licensed under the terms of the Creative Commons Attribution Non-Commercial License (http://creativecommons.org/licenses/by-nc/3.0/), which permits unrestricted, non-commercial use, distribution and reproduction in any medium, provided the work is properly cited. 